\title{
mELINTAS
}

31.1.2015 [1-12]

\section{WORLD CULTURAL STAGE AND RETRANSLATION OF LOCAL TRADITION}

\author{
Ignatius Bambang Sugiharto \\ Hadrianus Tedjoworo
}

\author{
| Department of Philosophy \\ Parahyangan Catholic University \\ Bandung, Indonesia
}

\begin{abstract}
:
Culture may transgress geopolitical boundaries. these days, especially when the survival of a certain community is under the threat of global political power, the need to overemphasize cultural uniqueness arises more strongly. Tradition is ambiguous and multi-interpretable, depending on the frame of interpretation, interest, power, and above all, on the dialectical encounter of 'translation': only in relation with something other and different, particular aspect of the tradition comes up. More than simply a matter of 'transmission', tradition is in fact a process of on-going 'transformation' and 'reinterpretation'. The world becames a huge stage where multiple waves of existence intersect and realize the complexity, ambiguity and subtlety of each other's world and of their own. In the interaction self-interrogation and mutual self-criticism take place, in which the participating cultures are called into question. In such global stage, cultures would weave and reweave their conceptual networks continually. The world cultural stage today is a never-ending conversation where traditions are not only rearticulated thereby, but also reinvented, and extended to their unpredictable potentialities in terms of new contexts. Culture lives in the conjunctions of our grammar of conversation happening on the stage.
\end{abstract}

Keywords:

world stage - culture - tradition - retranslation - transformation - ongoing reinterpretation - collaboration $\bullet$ conversation 
Today global interactions have compelled us to rethink the significance of our local cultures in terms of world cultural stage, and the other way round, the world cultural stage in terms of local traditions. This would mean also to rethink the significance of heritage in our present life. Cultures have never before been situated in a tug of war between centripetal and centrifugal forces as challenging as it is today. The centripetal would treat culture as a sanctuary or panacea for the troubled identity, whereas the centrifugal would take culture as a strategy for the transformation of self in new contexts and wider possibilities. While the former oftentimes shows not so much a realistic solution to the problem as a disguised helplessness in facing the global power, the latter seems to promise a more realistic response. How we are to see the world cultural 'stage' in correlation with local traditions will depend on how we conceive of culture, tradition and the meaning of 'stage' today.

\section{Culture}

Given the inevitability of cultural interaction today and the fact that thereby so many elements of our culture do change substantively, it would be more relevant to see culture as a process, instead of a system or a formal pattern. Culture is an historic process of plural influences and exchanges. It is a provisional imaginative picture of the junctions of various streams. What is primary is the flow, not the picture. Culture is a dynamic living flow. And as such it has its own internal principle of change. Culture consists of loosely connected elements that can be ordered and reordered in accordance with changing circumstances, such as when beliefs and values become incompatible with each other, politics is in tension between opposing visions and factions, new meaning subverts the old, and so on and so forth. Hence culture has its own indeterminacies, internal strains, conflicts and improvisations. It is a process of requests and counterrequests, of changing one's responses, and of innovating new expressions. It is also a struggle of power over meaning-giving to important aspects of life, such as problems of gender, private property, human rights, etc. Culture is a creative reordering and renewing capacity, processes of transmission and transformation, based on the existing condition and the possible. ${ }^{1}$ And this creative process of reordering, hence the process of transfiguration, 
of a culture mostly happens due to the dynamic relationship with the outer world, with 'others', that is, other cultures as well as the new phenomenon, the 'other', within the culture itself. To be more specific, culture keeps redefining and reinterpreting itself in terms of the other in the dialectic intercourse of cultural 'translation'. The significance of its particular values manifests itself only in the encounters of translation. Although a culture can be envisaged somehow as a certain whole, it is an internally fissured whole, a whole containing internal differences, including its own alternatives ("otherness"), and conceiving internal contestations.

The connection between culture and social community is not necessarily one to one. Culture may transgress geopolitical boundaries. In terms of culture some countries may be overlapping. In history the conflation of culture and social unit was oftentimes political: it served to legitimize the construction of a nation-state. And these days, especially when the survival of a certain community is under the threat of global political power, the need to overemphasize cultural uniqueness arises more strongly. In this respect, when according to Samuel Huntington what is political is basically cultural or civilizational, it would be better to see it the other way round that, what is cultural is basically political. ${ }^{2}$ In such context culture plays the role only as a temporary common focus for political engagement, a common reference binding various participants to struggle together for a common cause, not necessarily with common understanding of it. Further, culture - as a particular frame of mind and patterns of behaviour transmitted intergenerations - does not always serve as the principle of social order, since social order can be buttressed by technique of surveillance, systematic use of terror, effective economic system, educational institution or media of communication. ${ }^{3}$

\section{Tradition}

If culture is a creative reordering and renewing capacity, then, the capacity does not come out of the blue. It owes a great deal of its energy and intelligence from the collective past experience, namely, from the so called tradition. Tradition is a peculiar rationality, that is, a systemic effort to make the Lebenswelt -the flows of events or the multiformity of experience- intelligible. It is the inner struggle of collective human effort to give meaning to life experience in particular time and space, which 
eventually forms particular pattern of inner logic and inner feelings about life.

Tradition is an essential part of our spiritual biography, the collective unconsciousness that has shaped our inner perception, the tacit knowledge that has secretly helped us go through the changes. It serves as the innersetting, the hidden spiritual alphabet of our dealing with the deep mystery and the paradox of life : the perpetual motion and change.

There is no culture without tradition. Tradition does exist. But, the problem is, when it comes to the content and the essence of our tradition, the 'what' of it, things are never very clear. The content of a tradition is complex, its origin vague, its meaning polyvalent. In this sense tradition is ambiguous and multi-interpretable, depending on the frame of interpretation, interest, power, and above all, on the dialectical encounter of 'translation': only in relation with something other and different, particular aspect of the tradition comes up. When the partner of the dialectical encounter - hence the frame of translation - change, the significance, the substance, and the configuration of a tradition will also change. Walter Benjamin is correct when he said that, the significance of a tradition manifests itself only in the encounters of translation. We are all the potentialities that we have. What we call "our specific identity" is something we interpret and construct through relationship, by way of metaphors, figures, discourses, organizations and various forms of selfexternalization. Identity is in fact a transitory product of ongoing critical dialogical exchange with others. History, tradition and heritage of the past are all the data and interpretation that have constituted our way of living, that we have made use of, and that we are exposed to as an alternative among many others. History, tradition and heritage are not always objective representations of the past, but rather, possible interpretations of it, which are to be re-interpreted so as to transform us, to keep us on the move and to enable us to evolve to higher level. ${ }^{4}$ More than simply a matter of 'transmission', tradition is in fact a process of on-going 'transformation' and 'reinterpretation'.

One of the greatest partners of dialectical translation today is modernity (and postmodernity as its radicalization), by which every local tradition is challenged to translate its peculiar values into universal context or otherwise it vanishes into oblivion. While in the pre-modern condition 
it is tradition that controls personal reflection, in modernity it is the other way round. Modernity is characterized by the primacy of the Subject over tradition : it is personal reflection which now controls tradition. Modernity is an ongoing process of revaluation of any cultural traditions, and also of its own.

The Subject or self, however, is never a disengaged agent. In Heideggerian terms, the self finds itself and is able to define itself only in terms of a life shared with others, as being-together. ${ }^{5}$ And, following Merleau-Ponty, the most part of its perception is basically pre-conscious and pre-personal, materialized by a bodily ego which is also preconscious. ${ }^{6}$ It is precisely this archaic unity between the self and the world that manifests itself in the so called tradition. In this sense, tradition is not so much the overt systems and artifacts as the covert shared patterns of desire, emotion, imagination, evaluation and attitude behind them. The former are the configuration of the latter, yet the latter is a lot more ambiguous and complex than the former : the tacit patterns of desire and attitude is more amorphous than its configuration.

So, when tradition is put vis-à-vis modernity, and "traditional" means "pre-modern", we can see a significant difference of framework between the two. The encounter of translation between the two would change the very substance of both: tradition would be redefined, modernity re-evaluated. In this encounter what we call tradition or heritage is in fact some sort of transubstantiation of our past in terms of modern framework. What we call the substance or the content of 'our tradition' would depend on the way it is staged, imagined and presented, by who, and to which audience. When it is exhibited in a museum it becomes an art object and, like all masterpieces, is made idol, to be appreciated in contemplation, with disinterestedness and distance. And idols soon are transformed into ideas in discourse. On the other hand, unlike modern art objects, traditional artifacts originally do not belong to the realm of spectacle, in the sense that they are meant neither to be appreciated through watching, nor for contemplation of the sublime. They, instead, belong to the realm of event. It is not the object in itself, but rather, the event or the collective happening that counts. In such context, beauty, usefulness, pleasure, reflection and psycho-physical effects are all fused. ${ }^{7}$ An object is significant in so far as it presents the unpresentable, 
the absent, the mysterious ultimate being. The power does not lie in its conceptual meaning or virtuosity, but rather, in its emanation of being, in the collective spiritual-cognitive resonance it incites. It does not 'mean', it simply 'is'. And to appreciate means to partake in the sacrament of communion. In traditional art maximum utility is continually violated in favor of imagination and sheer caprice whereas beauty and contemplation are subordinated to usefulness and supernatural power. The energy of its creation is derived from the desire to take delight in everything we see and touch, a celebration of divinity working in and through banality. It is a fiesta of the object which transforms everyday utensils into a sign of communal participation. This explains the predominant penchant for decoration, while in modernity decoration is almost a crime. The imprint on the object is not personal signature, but rather, a faded scar commemorating the original brotherhood of man, the fact that the object is made by and for human collectivity, where soul searches for other soul and body for other body, in a mutually shared physical life. ${ }^{8}$

\section{World Stage}

Global modernization has enhanced cultural interactions. The revolution of communication and transportation has opened wider possibility for every culture to present itself or be presented by other. The world becames a huge stage where multiple waves of existence intersect and realize the complexity, ambiguity and subtlety of each other's world and of their own. In the interaction self-interrogation and mutual self-criticism take place, in which the participating cultures are called into question. In such global stage, cultures would weave and reweave their conceptual networks continually. Thoughts, emotions, symbols and self-awareness are time and again decomposed and recomposed through a process of translation, appropriation, resistance, subversion and compromise. It is a process of continuous translation of the Other into our own horizon, biography and collective consciousness, and the reverse, our own into the Other's. It is through, and by being exposed to, the Other, that we find our own hidden 'grammar' and spiritual 'alphabet'. Such cultural 'mise en scène' or 'translation' extends the boundaries of the participating traditions. We, thereby, are exposed to the possibility of interpreting anew our own cultural tradition as well as our personal narratives, hence a new 
possibility to give sense to life and an ongoing self-enlargement. ${ }^{9}$

Indeed the logic of negation or the logic of the "new" inherent in modernism would always compel cultural traditions to reformulate and translate their worldviews in terms of new frameworks of meaning, new demands and new opportunities. But the outcome of such process is not always alienating. Instead, it can also unmask the illusory character of a belief, unleash the long hidden potentiality of a tradition, and render manifest the unknown significance of a culture to their most abundant flowering. Neither it is to be perceived simply as leading to the re-integration of the core values of the respective cultures, as once envisaged by Samuel Huntington. It is, instead, a process of Deleuzian deterritorialization of meanings and values, a subtle and unpredictable process of ramification, which in turn might even change the very core value of the culture itself. ${ }^{10}$ Great civilization is always a rich synthesis of various cultures, an ongoing growth through the elaboration of otherness.

Cultural interaction is a process of self-enlargement. Vis-à-vis the other, or the Thou, we realize ourselves, we realize the imaginative variations of our ego, the playful metamorphosis of the ego. ${ }^{11}$ What emerges in the cultural stage is the truth that tells about both us and the other. And the truth becomes perceptible only through letting oneself "be told" by the other, being exposed to that otherness. This is an infinite relations. For the condition of the dialogue keeps changing, motivated by different interests, questions and prejudices. ${ }^{12}$ The world cultural stage today is a never-ending conversation where traditions are not only rearticulated thereby, but also reinvented, and extended to their unpredictable potentialities in terms of new contexts. And mostly it is the artist's role to carry out this task. It is their task to keep delving into the mysterious depth of traditions and put it into new dialogue with the latest perpectives. In their mise-en-scène the amorphous potential of a tradition is given form, the dialectic encounter with new context is brought into its most sensational effect.

In global cultural stage, therefore, what we can expect is the disclosure of possibilities for being and acting that emerge in and by means of playful encounters with the others. It is self-enrichment and greater selfrealization as a result of the play of meaning. Authenticity, then, is to be conceived as "being in the truth". We are in the truth when we are true to ourselves, when in the process of self-transformation we are able to 
incorporate our specific tradition and personal histories, that is, when our narratives are such as to contain a significant amount of ongoing coherence ; when in our rewriting and retelling we are able to preserve and take up the significance of the past with greater subtlety and complexity of narrative. We are authentic also when we are able to overcome the distortions systematic or otherwise- that constantly menace conversation; when we can maintain the openness of the conversation and keep it going. For it seems that what we most truly are, in our deepest inner self, is a conversation.

\section{Conversation}

Conversation is never singular. When interlocutors interact, subjectivity is turning into subjectivities, cultures are networked, and our retelling of realities becomes a neverending process of centrifugal interpretation. Mise-en-scène is not so much within a production context, as if we are always in control of the whole setting of the stage, as a collaboration that is continuously nurtured and influenced by the changing Other. It is both human and divine, individual and communal. In Deleuzian thought conversation is a very dynamic concept or event that is always moving and searching for entries and exits. It is a rupture from any traditional philosophical ways of mapping positions, searching for rational way out of a problem, reacting to and countering impediments, and surviving the debates. Conversation moves. It shows off the dynamic of collaboration in its most practical ways of cultural and conventional formations, rather than in its theoretical marks of the human mind. When performance is viewed as conversation in this sense, the artist enters a dialogue with the Other in an ongoing exchange of impressions. It is not so much about whose voice is the cantus firmus as the happening of "a double sympathy", "a correspondence of impressions multiplied by the desire for the pleasure of the Other". Conversation, then, transcends the mere contradiction among the subjects and particularities. The world as a cultural stage is not judging, for it simply alows the interests and impressions of different subjects to be satisfied and realized. If we think that the process of translation in each cultural performance is a personal effort happening subjectively, we might have missed the hermeneutical exchange conditioning translation. Tradition is always translated on the stage and put in tension between the local and the global. 
What happens on the local stage oftentimes is not a matter of cultural uniqueness, since the act of performing is a process of translating local impressions to the world and vice versa. The stage as a place of encounter and conversation gives rise to different sense of uniqueness when compared to the overlapping cultures. Deleuze's interpretation of Hume might reveal this sense when he says that "there are no physical objects of repetition except in the world. The world as such is essentially the Unique. It is a fiction of the imagination-never an object of the understanding". ${ }^{14}$ For those simply trying to find recognition of uniqueness through their performances on the stage this shift of the cultural toward the world could be shocking if not denigrating. One need not conclude that the age of the self is over. As anticipated above, culture is not so much a sanctuary as a more realistic strategy for the transformation of self in new contexts and wider possibilities. The world as a cultural stage connects local cultures without any intentions of judging their impressions. Its uniqueness lies in allowing the interconnections and even overlappings of the local cultures to reveal the process of transforming various identities. When 'conversation' happens on the stage, it is perpetual. Performance is not about proofing anything. What will destroy the stage - the world - are generalizations and closures. Freedom is the core of every stage in the world. Artists cannot be too certain of themselves, because otherwise proofing will take art's place. When there are certainties, we no longer need art let alone performance. The stage is a place for a perpetual conversation that correlates cultures, traditions, and the Other. Uniqueness belongs to the world and is impossible to possess by the generalizing subjects. It only can be tasted in the exchange of views, in being in relationship. Entering the stage, for the artists, is knowing that their identities are about to be transformed by conversations.

The world cultural stage is a world-wide-web of interactions and gazes that reveal differences not born of the controlling mind of the Father, but of the ever simbolical emotions of Mother Earth. The cultural stage needs no closure. It constantly opens relationships and creates the future. There is always a way out of each tension, but yet it will never be created. A way is given 'in time'. It is the emancipation of the stage from the meanings-loaded script of the director that will in turn gives space to the ways of the Other. The kenosis of the artists, as it were, projects blurry 
images of the absconditus Other. 'Conversation' on the stage is not the usual suspect of discourse, but rather, a timeless correspondence between the transcendent and the immanent, the divine and the human, the global and the local, Tradition and traditions. Today culture does not simply refer to geoculture. Culture lives in the conjunctions of our grammar of conversation happening on the stage. Yet when this conversation means a process of translation the emerging meanings and values cannot plainly be claimed geographically. The cultural stage has no ruler. It belongs to the Other. Instead of drawing boundaries the stage is erasing them, not in order that uniformity reigns, but rather, that identities are confirmed in relationships, in the gaze of the others.

Cultural retranslation of tradition becomes inevitable on the worldstage. It is a two-way experience. When tradition is understood beyond the past, that is, a process of on-going transformation and reinterpretation toward the future, wider possibilities are already imaged on the stage. The past and the future are both approaching us. We, ever connected as artists, are the new subject created in the Other's image. When we walk to the stage, we never know what will happen next. We might see the Other and the others face to face, but yet we are still alive and well. Cultural retranslation should scare no one. It simply nurtures our gaze and retells our story through the banal settings of the world.

\section{Bibliography}

Alperson, Philip (ed.). The Philosopby of the Visual Arts. New York: Oxford University Press, 1992.

Baynes, Kenneth., et al. (eds.). After Philosophy: End or Transformation. Massachusetts: MIT Press, 1987.

Bourdieu, Pierre. Outline of a Theory of Practice. Cambridge, U.K., New York: Cambridge University Press, 1977.

Deleuze, Gilles \& Guattari, Felix. Anti-Oedipus: Capitalism and Schizophrenia.

Trans. Robert Hurley et al. Minneapolis: University of Minnesota Press, 1986.

Deleuze, Gilles. Empiricism and Subjectivity: An Essay on Hume's Theory of

Human Nature. Trans. Constantin V. Boundas. New York: Columbia University Press, 1989. 
Dreyfus, Hubert, et al. Michel Foucault: Beyond structuralism and Hermeneutics. Chicago: University of Chicago Press, 1982.

Gadamer, Hans-Georg. Truth and Method. London: Sheed and Ward, 1975. Heidegger, Martin. Being and Time. Trans. John Macquarrie et al. New York: Harper and Row, 1962.

Huntington, Samuel P. The Class of Civilizations and the Remaking of World Order. New York: Simon \& Schuster, 1996.

Merleau-Ponty, Maurice. Phenomenology of Perception. Trans. Colin Smith. New York: The Humanities Press, 1962.

Merquior, José Guilherme. The Veil and the Mask: Essays on Culture and Ideology. London, Boston: Routledge and Kegan Paul, 1979.

Ricoeur, Paul. Hermeneutics and the Human Sciences: Essays on Language, Action, and Interpretation. Ed. \& Trans. John B. Thompson. Cambridge, New York: Cambridge University Press, 1981.

\section{Endnotes:}

1 Cf. Bourdieu, Outline of a Theory of Practice (Cambridge: Cambridge University Press, 1977) 8 .

2 Huntington basically sees political problems of the global world today as merely problems of identity rooted in the differences of civilizations. See Samuel P.Huntington, The Class of Civilizations and the Remaking of World Order (New York: Simon \& Schuster, 1996) 20-21.

3 Cf. J.G. Merquior, The Veil and the Mask: Essays on Culture and Ideology (London: Routledge and Kegan Paul,1979) 63-65.

4 Michel Foucault proposes an interesting notion that by way of re-interpreting our history, self can also re-create her/himself. This "Aesthetics of Existence" is in line with Nietzschean notion of self as a "work of art". See H. Dreyfus et al., Michel Foucault: Beyond Structuralism and Hermeneutics (Chicago: University of Chicago Press, 1982).

5 See Martin Heidegger, Being and Time, trans. John Macquarrie et al. (New York: Harper and Row, 1962) 61-62.

6 Cf. Maurice Merleau-Ponty, Phenomenology of Perception, trans. Colin Smith (New York: The Humanities Press, 1962) viii-xi.

7 Cf. Leon Rosenstein, “The Aesthetic of the Antique” in Philip Alperson (ed.), The Philosophy of the Visual Arts (New York: Oxford University Press, 1992) 404-405.

8 Octavio Paz writes beautifully on craftwork, comparing it with modern objects. This part is inspired very much by the article. See Octavio Paz, "Use and Contemplation," in ibid., 402-408.

9 Cf. Hans-Georg Gadamer, Truth and Method (London: Sheed and Ward, 1975) 345346.

10 In Deleuzian perspective meaning and values as inscription of desire and produced 
by various "desiring machine" are deterritorialized along with the Capitalist formation. The deterritorialization happens in such an unprecedented way that the previous social inscriptions is no longer needed. See Gilles Deleuze and Felix Guattari, Anti-Oedipus: Capitalism and Schizophrenia, trans. Robert Hurley et al. (Minneapolis: University of Minnesota Press, 1986).

11 Cf. Paul Ricoeur, Hermeneutics and the Human Science: Essays on Language, Action, and Interpretation, ed. \& trans. John B. Thompson (Cambridge, New York: Cambridge University, 1981) 94.

12 See Gadamer, "Forward to the Second German Edition of Truth and Method", in Kenneth Baynes, et al. (eds.), After Philosophy: End or Transformation (Massachusetts: MIT Press, 1987) 347.

13 Gilles Deleuze, Empiricism and Subjectivity: An Essay on Hume's Theory of Human Nature, trans. Constantin V. Boundas (New York: Columbia University Press, 1989), 37.

14 Ibid., 75. 